\title{
Gender Life Course Transitions from the Nuclear Family in England and Wales 1981-2001
}

\author{
by Lawrence Ware, Moira Maconachie, Malcolm Williams, Joan Chandler and Brian Dodgeon \\ University of Plymouth; Institute of Education
}

\author{
Sociological Research Online, Volume 12, Issue 4, \\ $<$ http://umw. socresonline.org.uk/12/4/6.html> \\ doi:10.5153/sro. 1544
}

Received: 17 Apr 2007 Accepted: 11 Jul 2007 Published: 31 Jul 2007

\begin{abstract}
In recent years there has been much political debate in the popular media about the fate of the nuclear family in the UK. Very little work has been done, using population data, to actually demonstrate the decline, or indeed continuance of this type of household formation. In this paper we use Office for National Statistics (ONS) longitudinal census data, from England and Wales, to explore the formation, dissolution and continuance of the nuclear family household over a twenty year period (1981-2001). Our findings indicate a continuing importance of this household arrangement, however routes into and trajectories from nuclear family households take different forms for men and women across the life course.
\end{abstract}

\section{Keywords: Nuclear Family; Households; Gender; Longitudinal Analysis}

\section{Introduction}

1.1 Despite recent rises both in numbers living alone and lone-parent families, a significant proportion of the population of England and Wales continue to live in nuclear family households. In 2001 over a third of residents in England and Wales lived in households that contained a couple with one or more dependent children. The break up and reformation of these types of household have the potential to affect a large proportion of the population with important implications for social structures and interactions. Alongside a research interest in the flux of household change and the dynamics of family life has come a greater interest in unusual family forms rather than normative family life (Silva and Smart 1999).

1.2 There is a large historical literature that suggests that the nuclear family household has a long history in England (Laslett and Wall 1972; Macfarlane 1978). The argument was reinforced in the early sociological work of Parsons, which described the cultural emphasis on the enduring links between parents and children and personal independence of adults within parent-child the wider socio-economic relations of capitalism which favour the formation of nuclear family households (Parsons 1949). As the predominant household arrangement in Western countries, and its changing nature (or even reduced prevalence) would have profound social and particularly social policy consequences. Much of the concern, whether arising from negative or positive views of these changes, has been directed to the immediate consequences for children, housing, employment, etc. But if family change is to be fully understood then the implications for different family members over their life course must be considered. For example, the intergenerational effects of property inheritance amongst 'first' or 'reconstituted' families, how labour markets will be shaped by and shape household forms, or recognising the more heterogeneous accommodation needs of individuals through their life course.

1.3 All of these issues can be informed by studying family and household change longitudinally through the individual life course. Life course analysis enables us to examine biographical change and the social impact of ageing, where individuals would be expected to move through different forms of households during their life time. Longitudinal analysis also enables us to distinguish anticipated from unanticipated change. The nuclear family household (comprised of a couple with dependent child/children) remains normative for those in their middle years, yet it might be seen as fragile and as more transitory than simple ageing would suggest. One question that emerges in the debate about its robustness as a family form is how much change in nuclear family households can be anticipated as a result of the departure of children and how much from dissolution into lone-parent and lone-person households. A secondary question answerable by longitudinal analysis is the extent to which the pattern of biographical change in the transformation and dissolution of households is itself changing. In 2001 over a third of residents lived in nuclear family 
households but how stable have these households been over the past 30 years and what other forms of households have men and women found themselves within?

1.4 In the present paper we focus on a key aspect of the transition from the nuclear family to other household forms, that of gender differences over the life course. It is, therefore, not our intention to review in any depth the history or the implications of family change, though we will begin with some orientating remarks. Instead we will concentrate on discussing the different household trajectories of partners resident in nuclear family households in 1981 over the next two decades. We do this through using census longitudinal data to follow the household transitions in 1991 and 2001 of such couples aged 16-44 in 1981 resident in England and Wales at that census point.

1.5 The paper begins by outlining the nature of the longitudinal data used and provides a summary of the types of household structure that were derived for the study. It then discusses some of the strengths and weaknesses of using these data to examine household structures and provides a brief outline of some of the assumptions about the different household structures. The first section of the analysis provides an overview of the changing nature of household structures in England and Wales from 1981-2001 and shows how these structures are related to the life courses of individuals. Following sections examine nuclear family households in more detail by tracing the life course differences between men and women experiencing transitions out of these households. The analysis provides evidence that the experience of men and women leaving nuclear families differ fundamentally at different stages of their life courses.

\section{Household Structure and the ONS Longitudinal Study}

2.1 The ONS Longitudinal Study (LS) is a $1 \%$ sample of linked individual census records from England and Wales for each Census from 1971 to 2001 . The total sample is around 900,000, around 500,000 at each census point. Initially, all people born on each of four dates in any year were selected from information given in the 1971 Census. From 1971, as new births occur on these four dates each year and as immigrants with those birth dates register with the National Health Service, these people join the LS. At each following census data relating to LS members and members of their household, has been added. Thus the LS is a true longitudinal study, a continuous sample from 1971. In this particular study our sample comprised all adults aged 16 to 44 in 1981 and enumerated at their home address at every Census from 1981 to 2001 inclusive. Thus this study sample allows us to track adult household moves, but selects out those moves made by children or elderly members of the $\mathrm{LS}^{[1]}$.

2.2 The household transitions are captured through the use of a Household Structure variable based on the building blocks of Minimal Household Units (MHU), originally derived by Overton and Ermisch (1984) and developed for the LS by Williams and Dale (1991) and Dale et al (1996). All households can be divided into one or more MHUs. The variable used here is based on a typology which also distinguishes MHUs on the basis of age and on the combination of MHUs in the same household. A dependent child is defined as under 16 years old, or under 19 years old but still in full-time education. Married couples are those who classified themselves as married in the census. The original household structure variable consisted of 12 categories $^{[2]}$, but for the purposes of this paper some of these are combined to produce a simplified seven category variable. The seven different household structures allow us to make certain assumptions about most or all of the LS members in each type of household. These assumptions in turn effect the conclusions that can be drawn about each household. The household structures and related assumptions about the LS members they contain are:

\section{Lone Person Households}

2.3 Lone person households contain one person aged between 16 and 64 years of age. For these households the LS member must be the lone person in the household.

\section{Lone Parent Households}

2.4 Lone parent households contain only one adult with dependent children. In most cases the LS member is the parent. In 1981, however, the LS member may be a child aged between 16-18 in full-time education.

\section{Multiple Adult Households}

2.5 Multiple adult households contain two or more non-coupled adults. These households can consist of two different types of cohabitational relationship:

1. The household may be comprised of two or more adults, none of which are a couple nor a parent and child. In this case the LS member may be any one of the adults in the household.

2. The household may be a lone parent with a grown up child. In this case, the LS member may be the 
parent or the grown up child. However, because there is a minimum age at which a parent can have a grown up child (approximately $16+16=32$ years old) for those in the sample aged 16-24 the LS member can only be the grown up child. For those aged 25-35 it is most likely that the LS member is the grown up child, while for those aged $35-64$ it is more likely to be the parent.

\section{Couple Only Households}

2.6 Couple only households contain no other persons than those in the couple. For these households the LS member may be either member of the couple.

\section{Couple with Adult Households}

2.7 Couple with adult households contain a couple with no dependent children but an additional adult. The additional adult may be either a grown up child or another adult. For these households the LS member may be either a member of the couple or the additional adult. If, however, the couple are the same age then the minimum age for which the additional adult is a child applies. For those aged $16-34$ the LS member is most likely a grown up child. For those aged 35-64 the LS member is more likely to be the parent.

\section{Nuclear Family Households}

2.8 Nuclear family households contain a couple with dependent child(ren) but no other persons. For these households the LS member may be either member of the couple, but not one of the children.

\section{Extended Nuclear Family Households}

2.9 Extended nuclear family households contain a couple with dependent children and an additional adult. As with the 'couple with adult households', the additional adult may be a grown up child or another adult. For those aged 16-34 the LS member is most likely a grown up child. For those aged 35-64 the LS member is more likely to be the parent. The LS member cannot, however, be a dependent child.

\section{Strengths and Weaknesses of using the LS}

3.1 The greatest strength of the LS is that it is the largest truly longitudinal data set in Britain that can track individuals through much, or the whole of their life course. With data available for each ten year census from 1971 to 2001 it is possible to track the life course of individuals to show not just their household transitions, but changes in their marital status, housing tenure, employment and numbers of children. In this paper we restrict ourselves to analysing adults present in nuclear family households in 1981 in order that we can compare the trajectories of LS members in different age bands. For example are there differences in the types of household movements of those aged 16-24 in 1981 with those aged 35-44 over the following two decades?

3.2 Because the LS is drawn from the England and Wales Census it has universal coverage with a response rate of around $98 \%$ and it is not geographically skewed. Even relatively small numbers will therefore be statistically significant (Hattersley and Creeser 1995). Although our sample mainly includes adults the presence of dependent children (aged 0-16) within the sample member's household is recorded. The 10 year interval between each census allows us to capture the presence of a dependent child within the household at two consecutive census points.

3.3 There are limitations to the LS, principally that it is a wholly descriptive dataset with no attitudinal data. It cannot tell us why people leave nuclear family households, nor why they choose or are constrained into living in subsequent household arrangements. However, analyses of household movements combined with other variables can provide important clues to behaviour and circumstances. The present research maps household transitions and therefore provides a useful basis for future attitudinal or detailed behavioural research.

3.4 Although the LS is a true longitudinal dataset, it nevertheless has the limitation that it consists of a set of snapshots. It is largely based on census enumeration and the household arrangement recorded on census night may be a very recent one, or it may be one that changes immediately after the census. These changes and more intermediate household transitions that occur during the period between censuses are unknown. The study will nonetheless suggest that people have a propensity to live in certain household structures the strength of which is dependent upon their age, sex and previous household structure. This effect is observable in the long term regardless of any short term fluctuations that occur. 
4.1 Diana Gittins conclusion that there were families and not 'the family' (Gittins 1993) has been a given in sociology since the demise of functionalist theories of the family in the 1980s, yet despite this the media have continued to report the decline of 'the family' and / or family values ${ }^{[3]}$. If 'the family' is taken to be the nuclear family form consisting of married parents living together with resident children, then there is evidence for the steady decline of this living arrangement (see Table 1). However, we must be careful not to conflate the decline of 'the family' with that of the decline of a particular family or household form. There is no necessary connection between residential living arrangements and the various social and emotional relationships that might constitute a family. Indeed as Allan and Crow (2001) note, precision in the use of the terms 'family' and 'household' is difficult to obtain because the terms in everyday life (and in sociology) are often conflated. Gittins notes that in many societies familial co-residence was not the norm (Gittins 1993: 61-4) and it is probably the case that the way people think about family nowadays has undergone change from the period when the nuclear family predominated in the mid 20th century (McRae 1999: 25). It is not our intention therefore to discuss families per se, but rather household change with a focus on nuclear family households. In this respect, what we term the 'nuclear family' is defined as a household arrangement where a man and a woman are co-resident with dependent children ${ }^{[4]}$. Our particular interest is to map the transitions of men and women when they enter or leave such an arrangement.

4.2 Whilst advocates of 'traditional family forms' see the decline of the (nuclear) family as a negative development arising from moral fecklessness, the reality is regarded by sociologists and demographers as both more complex in its origins and consequences. Moreover the patterns observed in Britain are, to a great extent, commonplace across Western countries. Since 1971 two of the most important changes to the household structure of England and Wales have been the growth of lone-person households and the decline of nuclear family households. The latter has been marked by a number of other attendant demographic changes to do with a later marrying age, a decline in numbers marrying, increase in divorce, decline in fertility and increase in the numbers of children born outside of marriage (Pullinger and Summerfield 1997). In the mid 1960s the mean age for marriage was 22, but by the mid 1990s this had risen to 26 (the same age as in the mid 1930s) and to 28.9 by 2004 (ONS 2006). The popularity of marriage has also declined. In 1972 there were just over 480 thousand weddings but by 2003 this had fallen to 308.6 thousand (though it increased to 311 thousand by 2004). Conversely cohabitation before marriage has increased from 4\% in 1966 to 68\% in 1993 (Pullinger and Summerfield 1997). Indeed in the 1990s over 70\% of new partnerships were cohabiting couples (Buck and Scott 1994). Patterns of childbirth have also changed. The percentage of people without children doubled from $10 \%$ to $20 \%$ and the fertility rate fell from 2.93 in the mid 1960s to 1.8 in the mid 1990s (McRae 1999: 2). In $198012 \%$ of all births in the UK were outside of marriage, but by 2004 this had increased to $42 \%$ (ONS 2006).

4.3 The changes summarised above are often described as the 'second demographic transition' (van de Kaa, 2002) and can be contrasted with patterns occurring before 1960. The second transition itself has been characterised by three phases (Scott 1999: 69). The first of these, between 1960 and 1970, was marked by increased divorce rates, the end of the 'baby boom' and a decline in fertility after the introduction of the contraceptive pill. In the second phase between 1970 and 1980 there was an increase in pre-marital cohabitation and numbers of children born outside of marriage. The third phase from the mid 1980s (and coinciding with our study period) has seen a stabilisation of divorce and a marked increase in cohabitation prior to marriage and after marriage break up.

4.4 Two important consequences follow from this: an increase in the number of persons living alone and an increase in lone parent households. Both of these household types have increased both prior to and after marriage and nuclear family formation. Yet, as we shall show below, the successor households to nuclear families are complex and are marked by different experiences for women and men and for different social classes.

\section{'His and 'Her' marriages and the consequences}

5.1 The expression 'his' and 'her' marriage was coined by Jessie Bernard (1972) to capture the different marital experiences of men and women. In particular she noted (1972: 5-11) that the recall of events within marriage (and courtship) is different for men and women and this led her to ask whether there could be such a thing as an 'objective marriage' or whether it was in fact two institutions populated by men and women respectively. Consequently power, privileges and duties are experienced differently by the parties and although the legal basis of marriage has shifted from a male hegemony, many of the divisions of labour, power and responsibility persist. Most importantly they persist even after the dissolution of marriage and the break up of the nuclear family household. This has consequences for the future household arrangements for both the men and the women, and any children. Although we do not have evidence either way, it seems reasonable to assume that such patterns and arrangements would hold true for nuclear family households where the adults are cohabiting. 
5.2 In particular, successor households formed after the break up of a nuclear family household are shaped by the presence of children and the division of labour in child care. Carol Smart (1999) describes the experiences of a group of fathers and mothers after divorce. She describes how prior to divorce fathers saw their role as that of breadwinner and their partner's as mother and homemaker (Smart 1999: 103). Although the mothers and fathers interviewed were from nuclear families dissolved in the 1990s, attitudes towards divisions of responsibility were those from an earlier time (particularly when many more mothers were not active in the labour market) and consequently the foundations of the post-nuclear family households' living arrangements and responsibilities were shaped within the nuclear family. On the break up of a marriage in the majority of cases the mother wins custody of the children and often retains the family home for a period after the break up. Thus the mother and the children constitute a lone-parent family and the father then either lives alone or joins some other household arrangement. It is this process and its household consequences that we now focus on.

\section{LS Sample Characteristics}

6.1 The sample used within the study comprises those LS members that were aged 16-44 in 1981 and were enumerated at the 1981, 1991 and 2001 Censuses. A total of 162,393 LS members fulfilled these criteria. The age of our sample increases at every census point. In 1991 the sample was aged between 26-54 and in 2001 between 36-64. To allow for comparisons between age bands, we further divided the sample into 3 separate age cohorts (16-24, 25-34 and 35-44 in 1981). As each age cohort is 10 years older at each census, this allows us to hold some age bands constant across census points. We can, for example, track changes that occur for 35-44 year olds across all three census points by comparing 35-44 year olds (1981 age) in 1981, with 25-34 year olds (1981 age) in 1991 and 16-24 year olds (1981 age) in 2001. However, we can only examine 16-24 year olds in 1981 and 55-64 year olds in 2001.

\section{[11] The Changing Nature of Household Structures 1981-2001}

7.1 Some of the most important changes to the household structure of England and Wales have been the growth of lone-person and lone-parent households. In many cases these households are the direct result of the break up of a nuclear family. The difference in life courses of men and women in nuclear families in England and Wales is to some extent reflected in changes of household structures within the study sample. Table 1 shows the proportion of the entire sample in each household structure from 1981 to 2001. The proportion of the sample living in nuclear families decreased steadily over the period. In $198141.8 \%$ of the sample lived in nuclear families. By 1991 the proportion had decreased to $37.4 \%$ and by 2001 fewer than a quarter $(23.7 \%)$ of the sample lived in nuclear family households.

Table 1 - Household Structure of sample 1981-2001

\begin{tabular}{llll}
\hline & \multicolumn{2}{l}{ Census Year/ } \\
& \multicolumn{2}{l}{ (Age of sample) } \\
Household Structure & $\mathbf{1 9 8 1}$ & $\mathbf{1 9 9 1}$ & $\mathbf{2 0 0 1}$ \\
\hline Lone Person & $\mathbf{1 6 - 4 4 )}$ & $\mathbf{( 2 6 - 5 4 )}$ & $\mathbf{( 3 6 - 6 4 )}$ \\
Multiple Adult & 2.9 & 6.5 & 11.2 \\
Couple Only & 6.3 & 4.0 & 3.2 \\
Nuclear Family & 10.7 & 18.4 & 28.2 \\
Extended Nuclear Family & 41.8 & 37.4 & 23.7 \\
Couple With Adult & 15.7 & 9.5 & 7.0 \\
Lone Parent & 10.4 & 13.8 & 13.6 \\
Extended Family (Complex) & 5.0 & 4.2 & 3.8 \\
Other & 1.1 & 5.4 & 5.5 \\
Total (\%) & $\mathbf{1 0 0 . 0}$ & 0.7 & 3.9 \\
$\mathbf{N}$ & $\mathbf{1 6 2 , 3 9 3}$ & $\mathbf{1 0 0 . 0}$ & $\mathbf{1 0 0 . 0}$ \\
\hline Source: ONS Longitudinal Study & & $\mathbf{1 6 2 , 3 9 3}$ \\
\hline
\end{tabular}

7.2 Not all of this decrease was due to the changing nature of household structures in the UK population over the period. Some of the changes instead reflect the increasing age of the sample between 1981 and 2001. In 1981 the sample was aged between 16 and 44. By 2001 the sample was aged between 36 and 64 . Some of the differences in the proportions of those living in each type of household over the period, therefore, may well be related to differences between the life courses of younger and older people. 
7.3 Table 2 shows the three age cohorts used in the study sample and the proportion living in nuclear families at each census point. As each cohort gets older, the proportion living in nuclear family households changes. The relationship between age and living in a nuclear family appears to be somewhat non-linear.

Table 2 - Nuclear Families 1981-2001 by Age in 1981

\begin{tabular}{llll}
\hline & \multicolumn{3}{l}{ Census Year } \\
Age in 1981 & $\mathbf{1 9 8 1}$ & $\mathbf{1 9 9 1}$ & $\mathbf{2 0 0 1}$ \\
\hline $\mathbf{1 6 - 2 4}$ & 15.9 & 47.7 & 49.4 \\
$\mathbf{2 5 - 3 4}$ & 55.4 & 48.1 & 18.3 \\
$\mathbf{3 5 - 4 4}$ & 53.2 & 13.7 & 2.8 \\
All (\%) & $\mathbf{4 1 . 8}$ & 37.4 & 23.7 \\
\hline
\end{tabular}

Source: ONS Longitudinal Study

\section{Decline or Stability in Nuclear Families 1981-2001?}

7.4 We can measure the extent to which the number of nuclear family households is changing in the UK over the period by controlling for the age of the sample. This is achieved by comparing each age band with their equivalent in the previous census year (i.e. comparing those aged 35-44 in 1981 with those aged 35-44 in 1991 and 2001). Table 3 shows the proportion of each age band that lived in nuclear family households at each census point. Because of the characteristics of the sample, there were no members aged 16-24 between 1991-2001 or members aged 55-64 between 1981-1991. We can, however, compare the remaining age bands at two or more census points. The proportion of 25-34 year olds living in nuclear family households declined from $55.4 \%$ in 1981 to $47.7 \%$ in 1991 . The proportion of $35-44$ year olds living in nuclear family households also decreased from $53.2 \%$ to $48.1 \%$ over the same period. This decline in nuclear families was not consistent over the period. By 2001 the proportion of 35-44 year olds living in nuclear families had increased to $49.4 \%$. Between 1991-2001 the proportion of 45-54 year olds living in nuclear families also increased from $13.7 \%$ to $18.3 \%$. Over time members of the sample both left and formed new nuclear family households.

\begin{tabular}{llll}
\multicolumn{5}{c}{ Table 3 - Nuclear Families 1981-2001 (\%) by Age in Census Year } \\
\hline \multicolumn{4}{c}{ Census Year } \\
Age in Census Year & $\mathbf{1 9 8 1}$ & $\mathbf{1 9 9 1}$ & $\mathbf{2 0 0 1}$ \\
\hline $\mathbf{1 6 - 2 4}$ & 15.9 & - & - \\
$\mathbf{2 5 - 3 4}$ & 55.4 & 47.7 & - \\
$\mathbf{3 5 - 4 4}$ & 53.2 & 48.1 & 49.4 \\
$\mathbf{4 5 - 5 4}$ & - & 13.7 & 18.3 \\
$\mathbf{5 5 - 6 4}$ & - & - & 2.8 \\
\hline
\end{tabular}

Source: ONS Longitudinal Study

\section{The continuation of nuclear families 1981-2001}

7.5 The members of nuclear families contained in our sample are those that lived in nuclear family households at each census point. The classification of those from nuclear families in 1981 that were living in a nuclear family by 1991 includes two types of member - those that remained in the same nuclear family over the period and those that experienced both a break up and re-formation of a nuclear family. A nuclear family can be re-formed both by members that are primary carers for any children and those that are not (the latter becoming 'step parents'). A total of $39.9 \%$ of the sample that were living in nuclear families in 1981 were living in the same type of household structure in 1991. Whilst this proportion increased by only 0.2 percentage points between 1991 and 2001 to $40.2 \%$, it does suggest the stability of this household form over that period.

7.6 Looking at the gendered pattern, shown in Table 4, we find that living within a nuclear family household was a more sustained experience for men than it was for women. A higher proportion of all men $(41.3 \%)$ from nuclear families in 1981 lived in the same type of household structure in 1991 than all women (38.7\%). The proportion of men from nuclear families in 1991 that also lived in nuclear families by 2001 increased to $42.1 \%$ while for women it decreased to $38.4 \%$. 


\begin{tabular}{llllllllllll}
\hline & \multicolumn{3}{c}{$\begin{array}{l}\text { Age of Men in Nuclear } \\
\text { Families }\end{array}$} & \multicolumn{4}{c}{$\begin{array}{c}\text { Age of Women in Nuclear } \\
\text { Families }\end{array}$} & \multicolumn{3}{c}{ All } \\
Transition Destination & $\mathbf{1 6 - 2 4}$ & $\mathbf{2 5 - 3 4}$ & $\mathbf{3 5 - 4 4}$ & $\mathbf{4 5 - 5 4}$ & All & $\mathbf{1 6 - 2 4}$ & $\mathbf{2 5 - 3 4}$ & $\mathbf{3 5 - 4 4}$ & $\mathbf{4 5 - 5 4}$ & All & \\
\hline Nuclear Family 1991 (\%) & 46.7 & 58.8 & 22.6 & & $\mathbf{4 1 . 3}$ & 58.5 & 48.6 & 15.2 & & 38.7 & 39.9 \\
Nuclear Family 2001 (\%) & 64.5 & 33.4 & 15.2 & $\mathbf{4 2 . 1}$ & & 57.4 & 24.3 & 6.4 & $\mathbf{3 8 . 4}$ & $\mathbf{4 0 . 2}$ \\
Source: ONS Longitudinal Study & & & & & & & & &
\end{tabular}

7.7 Gender differences are also evident for different age bands. A total of $46.7 \%$ of men aged $16-24$ from nuclear families in 1981 also lived in nuclear families by 1991 compared to $58.5 \%$ of women. As the proportion of men and women leaving or remaining in nuclear families must be equal we might expect these values to be the same. However, as women are more likely than men to be the primary carer of children when a nuclear family breaks up, they are also more likely to re-form a nuclear family if they subsequently re-couple.

7.8 Unlike the 16-24 year olds, a far higher proportion of men than women from nuclear families aged 25-34 in 1981 lived in nuclear families 10 years later (58.8\% compared to $48.6 \%$ ). This almost exact reversal of proportions appears to suggest that a high proportion of men aged 25-34 from nuclear families in 1981 formed nuclear families with women aged $16-24$ and visa versa. A similar gender difference is apparent 10 years later: more men than women aged 25-34 from nuclear families in 1991 were also living in nuclear family households in 2001 (64.5\% compared to $57.4 \%$ ). These differences may be due to average differences in the ages of couples with men tending to be older than their partners.

7.9 The relative difference between the proportion of men and women from nuclear families that lived in the same household structure 10 years later appears to increase with age. More men than women from nuclear families aged 35-44 in 1981 were also living in nuclear families by 1991 (22.6\% compared to $15.2 \%)$ and more men than women from nuclear families aged 35-44 in 1991 were also living in nuclear families by 2001 (33.4\% compared to $24.3 \%$ ). That smaller proportions of the sample are continuing to live in nuclear family households over time is not unanticipated as many dependent children of these families would have grown up and/or left home. Nonetheless these findings show more continuity in nuclear family households than we anticipated at the outset of the current study.

7.10 Thus paradoxically, during a period when there was a sustained increase in the numbers of loneperson households and lone-parent families (Chandler et al 2004), there has also been a 'strengthening' of the nuclear family as a household type. However it is important to note that this does not mean people will live in the same nuclear family through their child rearing years, as they may migrate to a second or subsequent nuclear family.

\section{Transitions from nuclear families}

7.11 The transition from nuclear families to other types of household highlights two changes of interest. The first is when the couple 'breaks-up' their relationship and the second change is the anticipated transition of nuclear family households into different household forms resulting from dependent children growing up and leaving the parental home. In many cases of nuclear family break up involving no others, both a lone-parent and a lone-person household will be created ${ }^{[5]}$. If others from outside the nuclear family are involved then this provides a basis for the formation of additional new households (which may be nuclear families). Those that move from a nuclear family may share accommodation with others or return to live with their parents or extended families. They may also form new couple households with or without dependent children. Although not pre-determined, the household structures that result from the break up of the nuclear family appear to follow a pattern which can be largely explained by the likelihood of women gaining custody of the children.

7.12 Transitions from a nuclear family household occur mainly when children grow up and/or leave home ${ }^{[6]}$. For these cases the resulting household structure would be a couple with no dependent children, a couple with an additional adult, or a couple with dependent children and an additional adult. These 'natural' transitions will occur mainly for those in the sample that are old enough to be parents of non-dependent children. A nuclear family may also make a transition to a household structure that contains an additional adult if, for example, an adult child returns to the parental home.

\section{The break up of nuclear family households}

(a) The formation of lone-parent households 
7.13 When nuclear families break up, lone-parent families are formed when no others are involved in the new household structure of those that care for the children. Table 5 illustrates how this experience differs for men and women from nuclear families in 1981 and 1991. The table shows for men and women from nuclear families, the proportion of each age band that were lone parents 10 years later. The final column shows the total proportion of all those from nuclear families that were lone parents 10 years later. Overall, the proportion of all those in the sample from nuclear families that experienced this transition increased from $4.1 \%$ in 1991 to $4.8 \%$ in 2001.

Table 5 Transitions from nuclear families in 1981 to lone-parent households

\begin{tabular}{llllllllllll}
\hline & \multicolumn{3}{c}{$\begin{array}{l}\text { Age of Men in Nuclear } \\
\text { Families }\end{array}$} & \multicolumn{5}{c}{ Age of Women in Nuclear } & \multicolumn{3}{c}{ All } \\
Transition Destination & $\mathbf{1 6 - 2 4}$ & $\mathbf{2 5 - 3 4}$ & $\mathbf{3 5 - 4 4}$ & $\mathbf{4 5 - 5 4}$ All & $\mathbf{1 6 - 2 4}$ & $\mathbf{2 5 - 3 4}$ & $\mathbf{3 5 - 4 4}$ & $\mathbf{4 5 - 5 4}$ All \\
\hline Lone Parent 1991 (\%) & 1.5 & 1.5 & 1.1 & & $\mathbf{1 . 3}$ & 11.0 & 7.3 & 3.1 & & $\mathbf{6 . 5}$ & $\mathbf{4 . 1}$ \\
Lone Parent 2001 (\%) & & 2.5 & 1.7 & 0.9 & $\mathbf{1 . 9}$ & & 11.8 & 4.7 & 1.2 & $\mathbf{7 . 8}$ & $\mathbf{4 . 8}$ \\
\hline
\end{tabular}

Source: ONS Longitudinal Study

7.14 Overall, women from nuclear families were far more likely than men to become lone parents. More women than men from nuclear families in 1981 were lone parents in 1991 (6.5\% compared to 1.3\%). Again more women than men from nuclear families in 1991 were lone parents by 2001 (7.8\% compared to 1.9\%). This difference is related to the fact that after the break up of the nuclear family women tend take on the role of primary carer for the children. This was particularly the case for women from nuclear families aged 16-24 in 1981. Almost one in every 10 of these women (11.0\%) were lone parents by 1991 . The likelihood of women experiencing this transition, as anticipated, decreased with age as women's fertility declines.

\section{(b) The formation of lone-person households}

7.15 Lone-person households are formed from the break up of a nuclear family when no others are involved in the new household established by those that do not have children living with them. Table 6 illustrates how this experience affects men and women. The table shows the proportion of men and women in each age band from nuclear families in 1981 and 1991 that lived alone 10 years later. Overall, only $2.4 \%$ of the sample from nuclear families in 1981 lived alone in 1991. The proportion experiencing this transition increased to $3.6 \%$ between 1991 and 2001. Men from nuclear families in 1981 and 1991 were slightly more likely than women to live alone ten years later (3.2\% compared to $1.7 \%$ in 1991 and $4.0 \%$ compared to $2.4 \%$ in 2001).

Table 6- Transitions from nuclear family households to lone-person households

\begin{tabular}{lllllllllllll}
\hline & \multicolumn{3}{c}{$\begin{array}{l}\text { Age of Men in Nuclear } \\
\text { Families }\end{array}$} & \multicolumn{5}{c}{ Age of Women in Nuclear } \\
Transition Destination & $\mathbf{1 6 - 2 4}$ & $\mathbf{2 5 - 3 4}$ & $\mathbf{3 5 - 4 4}$ & $\mathbf{4 5 - 5 4}$ All & $\mathbf{1 6 - 2 4}$ & $\mathbf{2 5 - 3 4}$ & $\mathbf{3 5 - 4 4}$ & $\mathbf{4 5 - 5 4}$ All & \\
\hline Lone Person 1991 (\%) & 8.8 & 2.7 & 2.5 & & $\mathbf{3 . 2}$ & 3.6 & 0.8 & 2.3 & & $\mathbf{1 . 7}$ & 2.4 \\
Lone Person 2001 (\%) & 5.4 & 4.6 & 5.0 & $\mathbf{4 . 0}$ & & 1.1 & 2.8 & 6.9 & 2.4 & $\mathbf{3 . 6}$ \\
Source: ONS Longitudinal Study & & & & & & & & &
\end{tabular}

7.16 As with lone-parent families, the difference between the proportion of men and women making a transition from nuclear family households to living alone is probably explained by the likelihood of women undertaking the role of primary carer of any children. Gender differences are particularly evident for those aged 16-24. A total of 8.8\% of men from nuclear families aged 16-24 in 1981 lived alone by 1991 compared to $3.6 \%$ of women. Higher proportions of men from nuclear families aged 25-34 and 35-44 lived alone 10 years later than women of the same age. For men and women, however, the proportions of both of these age groups living alone increased from 1991 to 2001. While for women, this increase was less than 0.5 percentage points for both age groups for men the proportions almost doubled. Although a higher proportion of men than women from nuclear families aged 16-44 lived alone 10 years later, this was not the case for the oldest age group. More women than men from nuclear families aged 45-54 in 1991 lived alone by 2001 (6.9\% compared to $5.0 \%$ ). Although the gender difference in the younger age bands can be accounted for by lone parenthood it is unlikely that this accounts for the higher proportion of women aged 45-54 experiencing the transition from nuclear families to living alone. This difference is more likely to be explained, for example, by widowhood or separation/ divorce after the children have left home.

\section{The continuity of nuclear family households into new forms of household}


7.17 Households containing a couple with no dependent children but an additional adult are formed from nuclear family households in two main ways. One of these is anticipated and occurs when the last sole dependent child of a couple living at home becomes an adult. The other occurs when an adult from a nuclear family household leaves and joins a household with an existing couple. This would occur for example should a member of a nuclear family household return back to the parental home when their own relationship breaks down. Over a fifth of the sample (20.8\%) that lived in nuclear families in 1981 resided in couple with adult households by 1991 (Table 7). This figure decreased by just over one percentage point by $2001(19.7 \%)$. Overall, there was little difference between the proportion of men and women experiencing this transition between 1981-1991 (21.1\% compared to 20.5\%) or between 1991-2001 (19.6\% compared to $19.7 \%)$

Table 7- Transitions from nuclear families to couple with adult households

\begin{tabular}{|c|c|c|c|c|c|c|c|c|c|c|}
\hline \multirow[b]{2}{*}{ Transition Destination } & \multirow{2}{*}{\multicolumn{4}{|c|}{$\begin{array}{l}\text { Age of Men in Nuclear } \\
\text { Families (1981 and 1991) } \\
16-2425-3435-4445-54 \text { All }\end{array}$}} & \multicolumn{4}{|c|}{$\begin{array}{l}\text { Age of Women in Nuclear } \\
\text { Families (1981 and 1991) }\end{array}$} & & \multirow[t]{2}{*}{ All } \\
\hline & & & & & $16-24$ & $25-3$ & $35-44$ & $45-54$ & All & \\
\hline $\begin{array}{l}\text { Couple With Adult } 1991 \\
(\%)\end{array}$ & 10.1 & 34.7 & & 21.1 & 3.5 & 13.6 & 38.2 & & 20.5 & 20.8 \\
\hline $\begin{array}{l}\text { Couple With Adult } 2001 \\
(\%)\end{array}$ & 6.0 & 25.5 & 33.6 & 19.6 & & 7.8 & 29.7 & 35.5 & 19.8 & 19.7 \\
\hline
\end{tabular}

Source: ONS Longitudinal Study

7.18 There was a relatively large gender difference in those from nuclear families aged 16-24 in 1981 that lived in couple with adult households by 1991 (9.3\% of men compared to $3.5 \%$ of women). We can make certain assumptions about these LS members, in particular that most of this group is comprised of children returning back to their parents (rather than the LS member being of the couple). This is because many 1624 year olds in 1981 were too young to have an adult child living with them by 1991, so the LS member must be the returning (grown up) child. In addition, it is anticipated that more men than women in this age band will return home to their parents after the break up of the nuclear family as women tend to take on the role of primary carer of children. As housing is generally prioritised for those with dependent children, men are more likely than women to leave the family home and find somewhere else to live. The younger age band may not have sufficient resources to establish their own lone-person household and so may be forced or prefer to return to their parents household.

\section{(b) Extended nuclear family households}

7.19 What might be termed 'extended nuclear family households' can form 'naturally' from nuclear family households when a couple has more than one child and one of their dependent children becomes an adult but continues to live at home. They can also form when an adult from a nuclear family that breaks up joins an existing nuclear family. This may occur, for example, when a member of a fragmenting nuclear family returns back to their parents before the remaining dependent children have grown up. A total of $17.3 \%$ of those that lived in nuclear families in 1981 resided in extended nuclear family households in 1991 (Table 8). Overall, there was little difference between the proportion of men and women experiencing this transition between 1981-1991 (17.7\% and 17.0\% respectively) and between 1991-2001 (14.1\% and $14.2 \%$ respectively).

Table 8 Transitions from nuclear families to extended nuclear households

$\begin{array}{lll}\begin{array}{ll}\text { Age of Men in Nuclear } & \text { Age of Women in Nuclear } \\ \text { Families } & \text { Families }\end{array} & \text { All }\end{array}$

Transition Destination $\quad 16-24$ 25-34 35-44 45-54 All $\quad 16-24 \quad 25-34 \quad 35-44 \quad 45-54$ All

\begin{tabular}{|c|c|c|c|c|c|c|c|c|c|}
\hline $\begin{array}{l}\text { Ext. Nuclear Family } 19913.3 \\
(\%)\end{array}$ & 18.9 & 19.7 & & $\begin{array}{ll}17.7 & 3.8\end{array}$ & 22.2 & 14.9 & & 17.0 & 17.3 \\
\hline $\begin{array}{l}\text { Ext. Nuclear Family } 2001 \\
(\%)\end{array}$ & 13.9 & 16.2 & 7.7 & 14.1 & 16.1 & 14.3 & 2.8 & 14.2 & 14.2 \\
\hline
\end{tabular}

7.20 Those from nuclear families aged 16-24 in 1981 that lived in extended nuclear families by 1991 were mainly the grown up children of the couple. A slightly higher proportion of women from nuclear families in 1981 were living in an extended nuclear family household by $1991(3.8 \%)$ than men (3.3\%). Similar proportions of women aged 16-24 experienced this transition as that to households without dependent children (i.e. couple with adult households) by 1991. In contrast, the proportion of men aged 16-24 that lived in extended nuclear family households by 1991 was 6.0 percentage points lower than the proportion living in couple with adult households. This suggests that after the break up of a nuclear family very few young 
women return to their parents regardless of whether or not their parents have dependent children. For young men this is not the case. Young men are almost three times more likely to return to their parents after the break up of a nuclear family if their parents do not have dependent children than if they do.

7.21 The proportions of men and women aged 25-34 from nuclear families in 1981 that lived in extended nuclear families by 1991 were both higher than those aged $16-24$. A total of $18.9 \%$ of men aged $25-34$ from nuclear families in 1981 lived in extended nuclear families by 1991 compared to $22.2 \%$ of women. Men and women aged 25-34 from nuclear families in 1981 were almost 6 times as likely to live in extended nuclear families by 1991 as those aged 16-24. This increase reflects the continuity of the nuclear family as dependent children grow up but continue to live at home.

7.22 More men than women aged 35-44 from nuclear families in 1981 lived in extended nuclear families by 1991 than women (19.7\% compared to $14.9 \%)$. This difference of almost 5 percentage points contrasts with the higher proportion of women this age than men living in similar households without dependent children (i.e. couple with adult households). As the key difference between these two types of households is the presence of dependent children, this suggests that (with the exception of lone parents) older women from nuclear families were less likely to continue to care for dependent children than were men. This trend continues for those from nuclear families aged $45-54$ that lived in an extended family 10 years later. The proportion of men experiencing this transition $(7.7 \%)$ was almost three times that of women $(2.8 \%)$. (c)

\section{Couple only households}

7.23 The formation of couple only households can occur in similar ways to those discussed above. One in 10 of those from nuclear families in 1981 (10.5\%) were living in couple only households by 1991 (Table 9). Between 1991-2001 this increased to 13.9\%. Overall there was little difference between the proportions of men $(10.6 \%)$ and women $(10.5 \%)$ from nuclear families in 1981 that lived in couple only households by 1991 (10.6\% and $10.5 \%$ respectively) and from 1991 to 2001 (14.2\% and $13.7 \%$ respectively). ${ }^{[7]}$

\section{Table 9 Transitions from nuclear families to couple only households}

\begin{tabular}{lllllllllll}
\hline & $\begin{array}{l}\text { Age of Men in Nuclear } \\
\text { Families }\end{array}$ & \multicolumn{5}{c}{$\begin{array}{l}\text { Age of Women in Nuclear } \\
\text { Families }\end{array}$} & \multicolumn{4}{c}{ All } \\
Transition Destination & $\mathbf{1 6 - 2 4}$ & $\mathbf{2 5 - 3 4}$ & $\mathbf{3 5 - 4 4}$ & $\mathbf{4 5 - 5 4}$ & All & $\mathbf{1 6 - 2 4}$ & $\mathbf{2 5 - 3 4}$ & $\mathbf{3 5 - 4 4}$ & $\mathbf{4 5 - 5 4}$ All & \\
\hline Couple Only 1991 (\%) & 18.6 & 4.9 & 14.6 & $\mathbf{1 0 . 6}$ & 14.3 & 4.0 & 18.5 & & $\mathbf{1 0 . 5}$ & $\mathbf{1 0 . 5}$ \\
Couple Only 2001 (\%) & 5.2 & 14.9 & 34.1 & $\mathbf{1 4 . 2}$ & & 3.5 & 19.5 & 41.1 & $\mathbf{1 3 . 7}$ & $\mathbf{1 3 . 9}$ \\
Source: ONS Longitudinal Study & & & & & & & & &
\end{tabular}

7.24 The likelihood of moving from a nuclear family to a couple only household appears to be related to the presence of children at different stages of the adult life course. Men and women aged 25-34 from nuclear families were least likely to live in couple only households 10 years later than any other age band $(4.9 \%$ and $4.0 \%$ respectively by 1991 , and $5.2 \%$ and $3.5 \%$ respectively from 1991 to 2001 ). Presumably these relatively low proportions are because men and women this age are more likely to continue in or re-form nuclear families (see Table 4).

7.25 There appears to be a distinct difference between the experience of men and women of the youngest and eldest age bands leaving nuclear families. A total of seven percentage point more women aged 45-54 from nuclear families $(41.1 \%)$ lived in couple only households 10 years later than men of the same age $(34.1 \%)$. This difference is probably due to the different experiences of men and women leaving nuclear families at this point in their life course. When women of this age form another couple relationship with a man it is unlikely that the man will be the primary carer of children and therefore more likely that the new household structure will be couple only household. As single women are more likely to be primary carers of children, when men form a new couple with a woman it is less likely to be a couple only household and more likely to be a nuclear family. This argument is also supported by the greater proportion of men from this age living in nuclear family households than women (see Table 4).

7.26 The converse of this argument appears to be the case for those aged 16-24. The proportion of men from nuclear families in 1981 that lived in couple only households by 1991 was $18.6 \%$ compared to $14.3 \%$ for women. This 4.3 percentage point difference is probably due to the dynamics behind the break up of younger nuclear family households. When young couples with children break up, the resulting household structures for men and women are different as women are more likely than men to form lone-parent households. When these women form another couple it will nearly always result in a nuclear family household regardless of whether their new partners have children or not. As men from nuclear families are less likely to be the primary carer of the children, their re-formation of a nuclear family will depend upon whether their new partner has children or not. As not all women will have children, men of this age are less 
likely to re-form a nuclear family than women of the same age.

\section{[III] Conclusions}

8.1 This paper examines the household transitions of members of the study sample who were in nuclear family households in 1981 and follows their household transitions over the following 20 year period. Over this period it identifies the gendered pattern of household transitions and reveals differences in the gendered pattern for younger and older age groups. When nuclear families of younger adults break up men were more likely than women to live alone or move back to their parents. They were also more likely to form a household with a new partner and no children. Women were more likely than men to become lone parents or form households with dependent children and a new partner. The pattern differs when nuclear families of older adults break up. Although women were still more likely than men to become lone parents they were also more likely to live alone, live in a couple with a grown up child, or live in a couple only household. Older men were more likely to form another family household with dependent children. Overall this study demonstrates the continuing importance of nuclear family households in people's lives and the increased likelihood of those living in nuclear family forms in their middle years to remain within them.

\section{Acknowledgements}

This article draws on research funded by the ESRC (RES-000-22-1413) under the Small Grants Scheme. The authors gratefully acknowledge the ONS for access to the Longitudinal Study.

\section{Notes}

${ }^{1}$ Women of 40 or older in 1981 would have reached retirement age by 2001.

${ }^{2}$ The original 12 category variable and its derivation is discussed in Dale et al (1996: 24).

${ }^{3}$ See Janssens, A (1997) for a review of the debate.

${ }^{4}$ These may also include children 16-19 not in education who are deemed 'non dependent'.

${ }^{5}$ For the few cases where both partners have custody of children two Lone-parent households would be created.

${ }^{6}$ We also re-classify a small number of nuclear families as "Other" when one of the parents is over 65.

${ }^{7}$ If we assume that the number of men and women in each age band in the population are equal, any percentage differences between the proportion of men and women in the same age band living in couple only households must be due to their partners being in different age bands. In fact the number of men and women in each age band in the population is not equal. The following table shows the number and proportion of men and women in England and Wales in each age band according to the 1981 Census. For all three age bands there were more men in the population than were women. The greatest difference was for $16-24$ year olds where the total number of women was $96.7 \%$ of the total number of men.

$\begin{array}{llll}\text { Age band } & \text { Males } & \text { Females } & \text { \% Females/ Males } \\ 16-24 & \text { N } 3,255,835 & 3,148,125 & 96.7 \\ 25-34 & \text { N } 3,293,311 & 3,261,698 & 99.0 \\ 35-44 & \text { N } 2,794,292 & 2,762,424 & 98.9\end{array}$

Given the higher proportion men than women aged 16-24, we would expect the number of men that are coupled in this age band to be $96.7 \%$ that of women. In 1981 the total proportion of women in the study sample aged 16-24 that lived in couples with no dependent children was $12.1 \%$. We would expect the proportion of men in the same household structure to be $11.7 \%$. The difference caused by more men than women for this age band is negligible. We therefore report the actual rather than weighted differences when comparing ages as if assuming that there were no difference between the number of men and women in each age band in the population. 
In 1981 the total proportion of women in the study sample aged 16-24 that lived in couple only households was $12.1 \%$ compared to $7.1 \%$ of men (Source: ONS Longitudinal Study). This 5.0 percentage point difference shows that at least this many more women aged 16-24 were coupled with older partners than men of the same age. All things being equal we would expect to see this difference reflected in the proportions in the other age bands. Indeed, for 25-34 year olds in 1981 there were 3.2 percentage points more men $(16.6 \%)$ than women (13.4\%) living in couple only households (Source: ONS Longitudinal Study).

The sample used in this study is representative of only those in the population between 16 and 44 in 1981 . Any overall difference that exists in the population between the proportion of men and women in couple only households must be due to their partners being younger than 16 or older than 44 in 1981. Over the entire sample, however, the net effect of these differences is almost zero. The proportion of women living in couple only households was $10.7 \%$ compared to $10.5 \%$ of men (Source: ONS Longitudinal Study).

\section{References}

BERNARD, J. (1972) The Future of Marriage. London: Souvenir Press.

BUCK, N and Scott, J (1994) 'Household and Family Change' in Buck, N; Gershuny, J; Rose, D and Scott, J (eds) Changing Households: The British Household Panel Survey 1990-91 . Colchester: ESRC Centre on Micro Social Change, University of Essex.

CHANDLER, J; Williams, M; Maconachie, M; Collett, T and Dodgeon, B (2004)'Living Alone: Its Place in Household Formation and Change' Sociological Research On Line Vol 93 http://www.socresonline.org.uk/9/3/chandler.html

DALE, A; Williams, M; Dodgeon, B (1996) Housing Deprivation and Social Change . London, HMSO. pp i-x; $1-127$.

GITTINS, D. (1993) The Family in Question: Changing Households and Familiar Ideologies. London: Palgrave Macmillan.

HATTERSLEY, L. and Creeser, R. (1995) LS Series 7: Longitudinal Study 1971-1991. History, organisation and quality of data (London: HMSO).

JANSSENS, A (1997) 'The rise and decline of the male breadwinner family? An overview of the debate ' International Review of Social History Vol. 42 1-23

LASLETT, P. and R Wall, R. (eds) (1972) Household and Family in Past Time. Cambridge: Cambridge University Press.

MACFARLANE, A. (1978) The Origins of English Individualism: Family, Property and Social Transition. Oxford: Blackwell.

MCRAE, S (1999) 'Introduction: family and household change in Britain' in McRae (Ed) Changing Britain: Families and Households in the 1990s. Oxford: Oxford University Press.

OVERTON, E. and Ermisch, J. 'Minimal Household Units', Population Trends No 35. London: OPCS

PARSONS, T. (1949) 'The Structure of the Family' in R Ashen (ed) The Family. New York: Haynor.

PULLINGER, J and Summerfield, C (eds.) (1997) Social Focus on Families. London: Office for National Statistics.

SCOTT, J (1999) 'Family Change: revolution or backlash in attitudes?' in McRae (Ed) Changing Britain: Families and Households in the 1990s. Oxford: Oxford University Press.

SILVA, E. and Smart, C. (eds) (1999) The new family. London: Sage.

VAN DE KAA, D.J. (2002) 'The Idea of a Second Demographic Transition in Industrialized Countries'. in Sixth Welfare Policy Seminar of the National Institute of Population and Social Security . Tokyo, Japan

WILLIAMS, M. and Dale, A. (1991) 'Measuring Housing Deprivation Using the OPCS Longitudinal Study' LS Working Paper 72. London: SSRU, City University. 